Artigo original

Hegemonia - Revista Eletrônica de Relações Internacionais do Centro Universitário

Unieuro

ISSN: 1809-1261

UNIEURO, Brasília, número 5, 2010

¿Recebido em: 26/11/2009

Revisado em: 15/12/2009

Aprovado em: 3/3/2010

\title{
A POLÍTICA EXTERNA DO GOVERNO VARGAS NO ESTADO NOVO
}

SANTANA, Welber Santos ${ }^{1}$

Resumo: O artigo discute como a política externa, considerada por alguns analistas como pragmática e ambígua foi utilizada pelo Estado Novo como um instrumento estratégico de desenvolvimento. Pretende mostrar até que ponto essa estratégia obteve êxito no projeto de desenvolver o país. O projeto de desenvolvimento esboçado nesse período estava centrado na industrialização. Pretende ainda mostrar como o cenário da Segunda Guerra auxiliou o desenvolvimento do projeto de Vargas.

Palavras-chaves: Política Externa; Estado Novo e Desenvolvimento.

Abstract: The article discusses how the Brazilian foreign policy, considerate for some analysts like paradigmatic and ambiguous, they had been used by the "New State" like a strategic instrument of development. Will be analyzed the benefits that the Brazil's project of development received with this strategic, considering that the process of industrialization was beginning. Pretend yet to show how the Second World War scenery's helps to the Vargas's development project.

Key-words: foreign policy, New State and Development.

\section{Introdução}

Analistas como Amado Cervo (1992) e Gerson Mora (1980) consideram que o pragmatismo e a ambigüidade, bem como a política de barganha, destacaram-se como traços característicos da política externa do governo Vargas, durante o período do Estado Novo. Este estudo pretende investigar em que medida tal política foi marcada

1 Bacharel em Relações Internacionais. 
Artigo original

Hegemonia - Revista Eletrônica de Relações Internacionais do Centro Universitário Unieuro

ISSN: 1809-1261

UNIEURO, Brasília, número 5, 2010

por essas orientações, sobretudo no que se refere às relações entre o Brasil, os Estados Unidos da América e a Alemanha no contexto da Segunda Guerra Mundial.

O objetivo do estudo é, portanto, analisar a controvérsia surgida em torno da política externa do governo de Vargas no Estado Novo, com o foco em suas características, particularmente nas relações estabelecidas com a Alemanha de Hitler, bem como com os Estados Unidos da América, que integraria o grupo dos países aliados e combatentes do nazismo, na época. Para tanto buscamos analisar a política externa praticada no Estado Novo, levando em consideração o ultranacionalismo que caracterizou o Estado brasileiro na época e discutir os fatores que levaram o Brasil a compor o grupo dos aliados contra Hitler.

Em se tratando de uma discussão sobre política externa do Brasil e sobre características a ela atribuídas, tal como ambigüidade e pragmatismo, o estudo em questão se fundamentou nas formulações das teorias de relações internacionais bem como o sistema de ator racional e o debate neo-realismo e neoliberalismo. Tal conceito foi pensando igual, a partir das proposições de Amado Cervo (1992) em suas análises sobre o período Vargas. Boris Fausto (1995) e Moura (1969) contribuíram com suas narrativas históricas da política externa brasileira. Por fim, Abreu (1990) enriqueceu o debate, acrescentando pertinentes análises sobre as questões políticas e econômicas do Estado Novo.

Esse trabalho justifica-se por buscar compreender a política externa empreendida por Getúlio Vargas no período do Estado Novo. Pretende-se assim conhecer melhor a participação do Brasil naquele conflito - $2^{a}$ Guerra Mundial - e alguns elementos característicos do "modo de atuar" do governo brasileiro em um determinado contexto. Na medida em que o tema suscita debates e controvérsias no 
Artigo original

Hegemonia - Revista Eletrônica de Relações Internacionais do Centro Universitário Unieuro

ISSN: 1809-1261

UNIEURO, Brasília, número 5, 2010

campo dos estudos dedicados aos elementos norteadores da política externa brasileira, em alguns momentos e eventos cruciais da história, esse estudo pretende contribuir para tais discussões e abordagens. Daí sua relevância para o campo do conhecimento das relações internacionais.

O trabalho está organizado da seguinte forma: no tópico I abordamos os antecedentes do Estado Novo. No tópico II analisamos os conceitos de ambigüidade e pragmatismo a partir de literatura proposta. No tópico III discutimos em que medida a política externa varguista foi marcada por essas orientações e que benefícios foram alcançados. Por fim, no tópico IV apresentamos as considerações finais do estudo, buscando comparar e relacionar traços da política externa varguista aos do governo atual.

\section{Antecedentes do Estado Novo}

Na visão de Fausto, "parecia que o país iria viver sob um regime democrático. Entretanto, pouco mais de três anos após ser promulgada a Constituição de $1934^{2}$. O golpe do Estado Novo frustrou essa esperança" (1995; 352).

Uma das características do Estado Novo foi o autoritarismo ${ }^{3}$, que durou de 1937 a 1945. Foi instaurado por um golpe de Estado que garantiu a continuidade de Getúlio Vargas à frente do governo central, tendo o apoio de importantes lideranças

\footnotetext{
$2 \square$ Informações subtraídas do site: http://www.cpdoc.fgv.br/nav_historia/htm/anos3037/ev_radpol_aib.htm,Acessado 10/11.

$3 \quad$ Na tipologia dos sistemas políticos são chamados de autoritários os regimes que privilegiam a autoridade governamental e diminuem de forma mais ou menos radical o consenso, concentrando o poder político nas mãos de uma só pessoa ou de um só órgão e colocando em posição secundária as instituições representativas. (STOPPINO, 2003, verbete: Autoritarismo In Dicionário de Política).
} 
Artigo original

Hegemonia - Revista Eletrônica de Relações Internacionais do Centro Universitário Unieuro

ISSN: 1809-1261

UNIEURO, Brasília, número 5, 2010

políticas e militares. Para entender como foi possível o golpe, eliminando-se as suas resistências, é preciso retroceder ao ano de $1936^{4}$.

Em 1936, e nos primeiros meses de 1937, a sucessão presidencial tomou conta do cenário político do país. Entretanto Vargas procurava adiar e esvaziar o debate e oficialmente não apoiou nenhum dos candidatos, pois ele e a cúpula militar tinham outros planos. O Partido Constitucionalista indicou o nome do governador de São Paulo, Armando de Salles Oliveira, para a presidência.

As forças situacionistas e o Partido Trabalhista Brasileiro (PTB) apresentaram o nome de José Américo de Almeida. O candidato contava com o apoio da maioria dos Estados do Nordeste e de Minas Gerais, além dos setores pró-Vargas em São Paulo e no Rio Grande do Sul (FAUSTO, 1995).

Por último, pela Ação Integralista Brasileira (AIB), surgiu o nome de Plínio Salgado. No começo de 1932, Plínio Salgado deu início à articulação entre grupos regionais simpáticos ao fascismo e ao mesmo tempo fundou, no mês de fevereiro, a Sociedade de Estudos Políticos (SEP), reunindo intelectuais de tendências políticas autoritárias. O sucesso dessas iniciativas levou à criação, em outubro daquele ano, da $\mathrm{AIB}^{5}$.

O integralismo se define como uma doutrina nacionalista cujo conteúdo era mais cultural do que econômico. Sem dúvida, combatia o capitalismo financeiro e pretendia estabelecer o controle do Estado sobre a economia. Mas sua ênfase maior se encontrava na tomada de consciência do valor espiritual da nação, assentando em princípios unificadores: “Deus, Pátria e Família” era o lema do movimento (Fausto, 1995; 353).

\footnotetext{
$4 \quad \square$ Informações subtraídas do site: http://www.cpdoc.fgv.br/nav_historia/htm/anos3037/ev_golpe_estado.htm,Acessado 9/11.

5 Informações subtraídas do site:http://www.cpdoc.fgv.br/nav_historia/htm/anos30-

37/ev_radpol_aib.htm,Acessado 10/11.
} 
Artigo original

Hegemonia - Revista Eletrônica de Relações Internacionais do Centro Universitário Unieuro

ISSN: 1809-1261

UNIEURO, Brasília, número 5, 2010

A disputa eleitoral desenvolveu-se em meio a um quadro repressivo, de censura e restrição da participação política. Para compreender este quadro, retomemos o ano de 1935. Em março de 1935 foi criada a Aliança Nacional Libertadora (ANL).

A ANL atenuava a formação de um governo popular, nacional e revolucionário, defendia a luta contra o imperialismo, a reforma agrária e das liberdades democráticas, a suspensão do pagamento da divida externa e o combate ao nazifascismo. Assim como a AIB a ANL, tornou-se um movimento de massa. Luís Carlos Prestes foi escolhido como presidente de honra ${ }^{6}$.

Fausto (1995), afirma que a criação da ANL se ajustou à nova orientação dada ao Partido Comunista Brasileiro (PCB), orientação essa que vinha da Internacional Comunista (I.O.), organização que definia a linha do movimento comunista diretamente de Moscou.

Em abril de 1935, Luís Carlos Prestes retorna clandestinamente ao Brasil, acompanhado por Olga Benário. No mesmo mês, o Congresso Nacional sentido-se incomodado pela presença dos comunistas na frente popular, aprova o projeto de Lei de Segurança Nacional, que definia os crimes políticos e sociais, e dava poderes especiais ao Presidente para reprimir atividades políticas conceituadas como subversivas. Em julho de 1935, Carlos Lacerda leu um manifesto de Prestes que apelava pela derrubada do "governo odioso" de Vargas e a tomada do poder por um governo popular, nacional e revolucionário. Dessa forma o governo ganha uma excelente oportunidade para fechar a

6 Idem. 
Artigo original

Hegemonia - Revista Eletrônica de Relações Internacionais do Centro Universitário

Unieuro

ISSN: 1809-1261

UNIEURO, Brasília, número 5, 2010

ANL, e assim o fez, através do decreto de 11 de julho de 1935, colocando a ANL na ilegalidade ${ }^{7}$.

Decorrente dos acontecimentos e das muitas prisões ocorridas depois do decreto de 11 de julho, o PCB dá início aos preparativos de uma prematura insurreição armada, que se deflagrou em 23 de novembro de $1935^{8}$.

Desde o lançamento da insurreição, tudo deu errado. Por informações falsas ou por precipitação, o levante foi desfechado em Natal em 23 de novembro e só dias depois no Recife e no Rio de Janeiro. Além da formação de um efêmero governo revolucionário popular em Natal, graves mas rápido confronto ocorreram na capital da República e no Recife (FAUSTO, 2006: 74).

Ainda segundo Fausto (1995), com o fracasso do levante comunista abre-se caminho para a escalada autoritária de Vargas. Getúlio conseguiu aprovação para uma série de medidas repressivas, como a decretação de estado de sítio ${ }^{9}$ em todo território nacional por 30 dias (prorrogado por mais 90 dias) e, posteriormente, de estado de guerra $^{10}$, que foi sucessivamente prorrogado até 1937. Criaram-se órgãos específicos para a repressão ao comunismo, encarregados de investigar a participação de funcionários públicos e outras pessoas em atos contra a instituição política e social.

$7 \quad$ Informações subtraídas do site: http://www.cpdoc.fgv.br/nav_historia/htm/anos3037/ev_radpol_aib.htm,Acessado 10/03.

8 Informações subtraídas do site: http://www.oab.org.br/hist_oab/primeiros_anos.htm, Acessado 10/03.

9 Suspensão temporária de certas garantias constitucionais determinada pela necessidade de defesa da ordem pública. Em sua vigência o Executivo assume poderes normalmente atribuídos ao Legislativo e ao Judiciário, e são estabelecidas restrições aos direitos dos cidadãos. Entre outras medidas, o governo pode determinar a obrigação de residência em localidade determinada, a busca e apreensão em domicílio, a suspensão de liberdade de reunião e associação e a censura de correspondência, imprensa e telecomunicações. Informações subtraídas site:http://www.cpdoc.fgv.br/nav_historia/htm/glossario/ev_gl_estadositio.htm, Acessado 10/04.

10 Situação em que uma nação, com ou sem declaração de guerra, inicia hostilidades contra outra suspendendo todas as garantias constitucionais consideradas direta ou indiretamente prejudiciais à segurança nacional. Em dezembro de 1935, uma emenda constitucional abriu a possibilidade de se equiparar a "comoção intestina grave", com finalidades subversivas das instituições políticas e sociais, ao estado de guerra. Foi com essas características que o estado de guerra foi decretado no Brasil nos anos de 1936 e $1937 . \quad$ Informações subtraídas do site: http://www.cpdoc.fgv.br/nav_historia/htm/glossario/ev_gl_estadoguerra.htm, Acessado 10/4. 
Artigo original

Hegemonia - Revista Eletrônica de Relações Internacionais do Centro Universitário Unieuro

ISSN: 1809-1261

UNIEURO, Brasília, número 5, 2010

Foi nessa conjuntura que se desenvolveram as disputas eleitorais: com Getúlio utilizando instrumentos de força criados para reprimir os comunistas e contra os que eram contrários ao "continuísmo" de seu poder, enfraquecendo-os ou neutralizando-os. Ao longo de 1937, para evitar algumas dificuldades, o governo interveio em alguns estados e no Distrito Federal (FAUSTO, 1995).

Com a publicação nos jornais, em 30 de setembro de 1937, de que o EstadoMaior do Exército descobrira um plano comunista - Plano Cohen - para a tomada do poder, preparava-se o terreno para instaurar o golpe ${ }^{11}$.

O Plano Cohen foi o pretexto para reacender o clima golpista. De acordo com Fausto (1995), o documento aparentemente era um "plano" fantasma a ser publicado no boletim dos integralistas, mostrando como seria uma insurreição comunista e como os integralistas reagiriam. Porém, o documento foi transformando em realidade, chegando às mãos da cúpula do Exército. No dia 30 de setembro de 1937 foi transmitido pela "Hora do Brasil".

Com a divulgação do Plano Cohen, Vargas aproveita para fazer com que o Congresso aprove o estado de guerra novamente. Getúlio recebeu apoio do comandante da III Região Militar, que decretou a federalização da Brigada Militar riograndense, e do deputado Negrão de Lima, que percorreu os Estados do Nordeste e Norte buscando apoio dos governadores para o golpe. Então, no dia 10 de novembro de 1937, o Congresso foi cercado por tropas da polícia militar que fecharam-no. Era o início do Estado Novo.

11 Informações subtraídas do site: http://www.senado.gov.br/comunica/historia/Rep09.htm, Acessado 11/11. 
Artigo original

Hegemonia - Revista Eletrônica de Relações Internacionais do Centro Universitário Unieuro

ISSN: 1809-1261

UNIEURO, Brasília, número 5, 2010

De acordo com Cervo, "o advento do Estado Novo foi bem acolhido em

Berlim e Roma, em razão da identidade ideológica de seus governos com o novo regime. Em Washington houve apreensão, num primeiro momento" (1992; 225). Entretanto, Vargas demonstrou sua disposição para não promover grandes mudanças na política externa do país, nomeando Osvaldo Aranha (embaixador em Washington durante o golpe de 1937) para o Ministério das Relações Internacionais, pois este tinha uma posição de prestígio junto às autoridades norte-americanas.

Segundo Fausto (1995), os militares exerceram pressão junto ao governo para um entendimento com os alemães e acabaram ganhando um contrato para fornecimento de artilharia, com a Krupp ${ }^{12}$, em março de 1938. A simpatia de Getúlio pelos regimes totalitários europeus, fez com que ocorresse um aumento considerável das relações comerciais do Brasil com a Alemanha. Apesar disso, ocorreu uma crise diplomática entre os dois países, pois o Estado Novo investiu contra os grupos nazistas do Sul. O atrito chegou a tanto que, o embaixador alemão tornou-se persona non grata no país.

A relação do Brasil com os Estados Unidos melhorou muito após a nomeação de Osvaldo Aranha para o Ministério do Exterior, devido à crise BrasilAlemanha. Os Estados Unidos estavam preocupados com o aumento das relações comerciais entre Brasil e Alemanha e com a propaganda ideológica do Partido Nazista (CERVO, 1995).

\section{Sobre Ambigüidade x Pragmatismo}

12 Dinastia de industriais que está à cabeça do consórcio siderúrgico militar na Alemanha. Participaram activamente na preparação da Primeira Guerra Mundial (1914-1918) e na Segunda Guerra Mundialapoiaram Hitler.Informações subtraídas do http://www.marxists.org/portugues/dicionario/verbetes/k/krupp.htm, Acessado: 15/11. 
Artigo original

Hegemonia - Revista Eletrônica de Relações Internacionais do Centro Universitário Unieuro

ISSN: 1809-1261

UNIEURO, Brasília, número 5, 2010

De acordo com Cervo (1992), certa ambigüidade marcava o governo brasileiro às véspera do início do conflito na Europa, refletindo a divisão existente na própria cúpula do sistema político, entre pró-Eixo e pró-Aliados. As relações internacionais naquele momento caracterizavam-se por uma política eqüidistante e pragmática, na aproximação simultânea com os Estados Unidos e Alemanha.

Segundo Moisés (1974), a palavra ambigüidade vem do latim, ambiguitas, tatis, e ambíguo, e significa, "que apresenta duas faces, dois sentidos." Para o Dicionário Aurélio (2006), ambíguo: "que se pode tomar mais de um sentido; equívoco. Cujo procedimento denota insegurança; indeciso (...)".

A coexistência de mais do que um entendimento ou de que uma interpretação face à um determinado símbolo ou face a uma certa mensagem.(...) A existência de mais do que um significado para uma simples palavra ou para uma expressão - Ou ainda para uma atitude . Os discursos políticos são normalmente ambíguos, visando convencer ou atrair um mais largo espectro de auditores $(. . .)^{13}$.

O termo "pragmática" é derivado do grego pragma, significando coisa, objeto, principalmente no sentido de algo feito ou produzido, sendo que o verbo racein, significa precisamente agir, fazer. Os romanos traduziram pragma pelo latim res, o termo genérico para coisa, perdendo talvez com isso a conotação do fazer ou agir presente no grego ${ }^{14}$.

13 Informações subtraídas do http://farolpolitico.blogspot.com/2007/05/ambiguidade.html, Acessado11/11.

$14 \square$ Informações subtraídas do http://publique.rdc.puc-rio.br/revistaalceu/alceu_n1_Danilo.pdf, Acessado 23/11. 
Artigo original

Hegemonia - Revista Eletrônica de Relações Internacionais do Centro Universitário Unieuro

ISSN: 1809-1261

UNIEURO, Brasília, número 5, 2010

Ainda segundo o Dicionário Aurélio (2006), pragmático: “diz-se de pessoas, atitude ou projeto que é objetivo, direto, eficiente. Pragmatismo: Doutrina segundo a qual as idéias são instrumento de ação que só valem se produzem efeitos práticos.

Conforme Moura (1991), a possibilidade de o Brasil estabelecer direção própria em sua política externa e os graus de liberdade que pode exercer na tomada de decisões sobre relações internacionais tem sido motivo de preocupações de diplomatas, cientistas políticos e economistas, entre outros. Tornando-se restritas as manobras de política externa, entretanto, é importante frisar que não se pretende tecer aqui um panorama completo das relações externas do país durante o período delimitado, mas apresentar uma análise da postura do governo Vargas frente aos Estados Unidos e Alemanha.

De acordo com (Allison, 1999 apud Simões, 2004, p. 4), subtraídas da formulação de seu sistema de ator racional, o autor fundamenta a base do realismo clássico partindo do pressuposto de racionalidade consubstanciada em quatro considerações: (I) para os realistas os atores internacionais são os Estados Nacionais; (II) há uma racionalidade nas condutas dos Estados, tomando suas posições em base de análise dos benefícios e custos das diferentes opções, escolhendo a opção que maximiza os benéficos; (III) o cenário internacional e visto como uma "selva", tal como Hobbes concebia; (IV) o interesse dos Estados é sempre definido em termo de poder e segurança.

Ainda segundo Simões (2004), a teoria de ator racional envolve-se em explicar os preceitos das decisões estratégicas complexas, baseando-se no fato de que são feitas deliberações racionais para a tomada de decisões pelos governos nacionais. 
Artigo original

Hegemonia - Revista Eletrônica de Relações Internacionais do Centro Universitário Unieuro

ISSN: 1809-1261

UNIEURO, Brasília, número 5, 2010

Sobre a ótica das teorias neo-realismo e neoliberalismo a cooperação é possível. Porém, para os neo-realismos a cooperação está intimamente ligada á conseqüência da anarquia no sistema internacional, a estrutura anárquica obriga que os Estados pensem egoisticamente, ou seja, um Estado pode ameaçar a sobrevivência do outro. Decorrente disso limita-se o estímulo dos Estados para a cooperação. Para o neorealismo a cooperação ocorre quando e enquanto os interesses egoísticos dos Estados forem atendidos por esse arranjo, sendo difícil de ser construída e mantida a cooperação para os neo-realistas. (SARFATI, 2005)

Para os neoliberais a cooperação é o único meio para o conflito, devemos julgar sob quais cenários aumenta a probabilidade de cooperação internacional. A cooperação aumenta quando existem assuntos de interesses entre os Estados (SARFATI, 2005). "Há situações em que os Estados podem ter interesses comuns e nas quais, dependendo como o contexto da interação está estruturado, o resultado pode ser a cooperação, e não o conflito" (NOGUEIRA, 2005, p. 91). De acordo com Sarfati (2005), no contexto da Segunda guerra Mundial, o Brasil ficou do lado dos aliados em troca de benefícios econômicos que incluía a construção da indústria siderúrgica de Volta Redonda por parte dos norte-americanos. "Sabemos que é da natureza dos sistemas, especialmente sistemas complexos como o internacional, vincular seus componentes em um ambiente de interação estratégica" (NOGUEIRA; 2005, p. 91).

\section{Política Externa 1939 a 1945}


Artigo original

Hegemonia - Revista Eletrônica de Relações Internacionais do Centro Universitário Unieuro

ISSN: 1809-1261

UNIEURO, Brasília, número 5, 2010

De acordo com Cervo (1992), o governo brasileiro tinha como essencial para o desenvolvimento nacional o aumento das exportações, e a construção de uma usina siderúrgica. E ainda, havia o anseio de reorganizar as Forças Armadas.

“A relação que o Brasil mantinha nos anos 30 com os EUA e a Alemanha era muito particular: o governo Vargas explorava as possibilidades oferecidas por ambos os centros, sem optar por uma aliança clara com um dos dois" (MOURA, 1991, p. 6). Com isso, nos últimos anos da década de 1930, os Estados Unidos se mostraram preocupados com o crescimento das relações comerciais entre Brasil e Alemanha, cuja base residia nos acordos de comércio de compensação ${ }^{15}$ estabelecido entre os dois países $^{16}$.

Tais fatos, e ainda a aproximação da Segunda Guerra Mundial, promove a iniciativa do governo norte-americano de formular um convite de visita do ministro das Relações Exteriores brasileiras aos Estados Unidos. Organizou-se, a missão Aranha, que esteve nos Estados Unidos em fevereiro/março de 1939 (CERVO, 1992).

Com base em Abreu (1990, p. 92), a missão Aranha aos Estados Unidos caracterizou-se como o início de um longo período de relações "especiais" entre o Brasil e os Estados Unidos. Na agenda da missão constavam itens relacionados à defesa nacional, relações comerciais, à dívida externa e ao tratamento recebido pelos investimentos diretos norte-americanos no Brasil e assuntos ligados à política cambial. “O objetivo daquelas autoridades era, por meio da assistência econômica, atrelar o Brasil ao sistema de poder de seu país. Tal objetivo não se limitava ao Brasil; fazia parte

$15 \square$ "Eventuais saldos comerciais bilaterais resultariam na acumulação de depósitos inconversíveis em mil reis ou marcos compensados caso Alemanha ou Brasil vendessem mais do que comprassem no outro mercado" (ABREU,1990, p.88).

16 Informações subtraídas do http://www.cpdoc.fgv.br/nav_historia/htm/anos3745/ev_estecon_aranha.htm, Acessado em 10/04/2009. 
Artigo original

Hegemonia - Revista Eletrônica de Relações Internacionais do Centro Universitário Unieuro

ISSN: 1809-1261

UNIEURO, Brasília, número 5, 2010

da política de boa vizinhança, inaugurada pelo presidente Franklin D. Roosevelt" (Cervo, 1992, p. 230).

Os resultados da missão Aranha ficaram aquém dos esperados, especialmente entre militares, pois com o argumento de que a retomada dos pagamentos do serviço da dívida interferiria com as importações de equipamentos militares (ABREU: 1990, p. 93).

No dia $1^{\circ}$ de setembro de 1939 eclode a Segunda Guerra Mundial, Alemanha de Hitler, invade a Polônia. A França e Grã-Bretanha fazem uma advertência, entretanto, não houve retorno e no dia 3 do mesmo mês, ambas as potências declararam guerra ao regime de Hitler (MOTA: 1998).

Segundo Moura (1980), Getúlio, prudentemente, preferiu a neutralidade face à guerra. O governo mantinha relação comercial com Alemanha e enquanto crescia o intercâmbio com os Estados Unidos, Vargas tratava de manter a eqüidistância. Pois dispunha dos seguintes elementos de barganha: o fornecimento de armas já encomendadas da Alemanha e aceitaria novas encomendas, as empresas alemãs estavam capacitadas para montar uma usina siderúrgica completa no Brasil; enquanto o governo norte-americano não tinha capacidade para fornecer armas e as empresas norteamericanas se esquivavam da proposta de montar uma usina siderúrgica no Brasil.

Cervo (1992), no período de 23 a 30 de setembro 1939, reúne-se a primeira conferência pan-americana - I Reunião de Consultoria do Panamá - decorrente da guerra européia e adotou-se a posição de neutralidade do continente, evitando - se assim, a possibilidade de atos de guerra próximo do litoral do Continente Americano.

Entretanto, com a eclosão da guerra surgiu vários problemas para o Brasil: no plano econômico, mais especificamente, o bloqueio naval inglês, diminuindo 
Artigo original

Hegemonia - Revista Eletrônica de Relações Internacionais do Centro Universitário Unieuro

ISSN: 1809-1261

UNIEURO, Brasília, número 5, 2010

significativamente o importante intercâmbio comercial com Alemanha até o final de 1940. Ainda assim, “o poder de barganha de Vargas ainda não estava totalmente esgotado, principalmente, por causa das vitórias alemãs no teatro de operações" (IDEM).

O ministro das Relações Exteriores sugeriu que o governo fizesse condenações públicas referentes ao ataque alemão em abril de 1940, entretanto, Vargas preferiu a neutralidade em razão de que a Alemanha poderia ser fornecedora dos armamentos militares que o Brasil necessitava. Em maio ocorreu à invasão da Holanda, Bélgica e Luxemburgo, e o governo brasileiro reafirmou sua neutralidade (Cervo, 1992).

Com as vitórias que os exércitos de Hitler foram acumulando, entusiasmaram os simpatizantes do regime na América Latina promovendo mobilização de esforço em apoio ao Terceiro Reich. No Brasil, os militares, como, Dutra e Góis Monteiro, tinham uma admiração pela máquina de guerra alemã. Os Estados Unidos adotou uma série de medidas, criando o OCIAA (Office of the Coordinator of InterAmerican Affairs), ficando a cargo de Nelson Rockefeller, era uma tentativa de contrabalancear as propagandas do Eixo nas Américas. Os objetivos da OCIAA: persuadir as nações Latinas, integrar a economia do continente com as dos Estados Unidos, impedir revoluções na América Latina, lutar contra os agentes do Eixo e aumentar o comércio dos Estados Unidos (MOURA, 1980).

Para alcançar suas finalidades, o OCIAA utilizou-se: imprensa, através de artigo para jornais, fornecimento de fotografia e notícias; cinema, eliminação da competição alemã, estímulo à produção de noticiários sobre a América Latina. Personagens como: Zé Carioca, Panchito e Pato Donald, o chamado American Way of 
Artigo original

Hegemonia - Revista Eletrônica de Relações Internacionais do Centro Universitário Unieuro

ISSN: 1809-1261

UNIEURO, Brasília, número 5, 2010

Life passou a permear, de forma marcante, as culturas dos povos latino-americanos. Oficialmente, a "política de boa vizinhança", enquadra-se nesse esforço de aproximação pan-americana e solidariedade hemisférica (IDEM).

Em junho de 1940 é realizada a Conferência de Havana, acordou-se que qualquer tentativa de um Estado não-americano contra a soberania ou independência do Continente Americano seria considerada ato de agressão (MOURA, 1980)

Em 11 de junho do mesmo ano, Vargas pronuncia o famoso discurso a bordo do encouraçado "Minas Gerais" para a cúpula da hierarquia militar. No qual fez elogios aos sistemas totalitários de governos e previu o fim das democracias. "As nações fortes que se impõem pela organização baseada no sentimento da Pátria e sustentando-se pela convicção da própria superioridade" (Vargas, 1941). O discurso repercutiu amplamente tanto interna quanto externamente. Nos países do Eixo, foi acolhido um indicativo que o Brasil se manteria neutro. Enquanto, que nos Estados Unidos a reação foi de espanto e consternação, ainda que, Getúlio junto ao Departamento de Imprensa e Propaganda (DIP) do Estado Novo ter feito constar que discurso dirigia ao público, e nas vias diplomáticas Vargas fez constar que o Brasil não se afastaria da solidariedade panamericana. No dia 25 do mesmo mês, Getúlio pronúncia outro discurso reafirmando os termos do discurso de 11 de junho ${ }^{17}$.

\footnotetext{
Vargas não enxergava incoerência entre as faces interna e externa da política. Além disso, se o discurso de 11 de junho despertasse receio em Washington, tanto melhor. Melhor para o Brasil negociar, fazer andar as negociações brasileiro-americanas sobre a cooperação econômica e militar. Dispunha o Brasil de pouco trunfos. A conjuntura internacional estava propícia. Na marcha dos conflitos, aquele era o momento certo. Vargas forçou, assim, o
}

$17 \square$ Informações subtraídas do http://www.cpdoc.fgv.br/dhbb/verbetes_htm/5458_24.asp, Acessado em 10/04. 
Artigo original

Hegemonia - Revista Eletrônica de Relações Internacionais do Centro Universitário Unieuro

ISSN: 1809-1261

UNIEURO, Brasília, número 5, 2010

andamento das negociações: ou Washington coopera, e logo, ou abre-se caminho à cooperação alemã” (CERVO, 1992 p. 238).

O discurso de 11 de junho atingiu o alvo, o governo alemã, autorizou o embaixador no rio, Kurt Prüfer, a negociar diretamente e secretamente com Vargas, uma transação de trezentos milhões de marcos e a construção de uma siderúrgica no país. Ao mesmo tempo a postura dos Estados Unidos mudou, mostraram disposição para dar andamento ás conversações com o Brasil. Osvaldo Aranha enviou aos Estados Unidos, uma delegação para concluir as negociações. E ao final de setembro o governo norteamericano autorizou as solicitações brasileiras quanto à construção da usina siderúrgica de Volta Redonda, autorizando o Eximbank a conceder o empréstimo de 20 milhões de dólares e a tecnologia para a construção da siderúrgica ${ }^{18}$.

Segundo Moura (199: p. 11), a posição do Brasil no Atlântico tinha uma importância para a estratégia dos Estados Unidos, pois o Nordeste brasileiro poderia ser um ponto de apoio de operações caso a Alemanha derrotasse as forças da Grã-Bretanha no Norte da África. Assim, assinou-se um acordo criando a Missão Naval e a Missão de Aviação Militar dos Estados Unidos no Brasil. E em 1941 Vargas, autoriza a construção de bases militares no Nordeste brasileiro visando garantir a integridade do continente. A imprensa americana ressaltou a importância das bases militares no Brasil, e os gastos necessários para modernizar e a construção de bases militares (CERVO: 1992 p. 239).

No decorrer de 1941, a aproximação com os Estados Unidos acentuou-se. Vargas mostrou-se um ótimo articulador. Pois, em 20 de abril, enviou felicitações de aniversário, através de um telegrama a Hitler. Getúlio sabia que Washington

18 Informações subtraídas http://www.cpdoc.fgv.br/dhbb/verbetes_htm/5458_25.asp, Acessado em $10 / 04$. 
Artigo original

Hegemonia - Revista Eletrônica de Relações Internacionais do Centro Universitário Unieuro

ISSN: 1809-1261

UNIEURO, Brasília, número 5, 2010

demonstraria maior interesse pelo Brasil "se pairasse no ar alguma dúvida sobre a posição do país"17.

Enquanto, mandava felicitações a Führer, negociava com os Estados Unidos um acordo de suprimento de matérias-primas estratégicas (bauxita, berilo, cromita, ferro-níquel, diamante industriais, minério de manganês, mica, cristais de quartzo, borracha, titânio e zircônio) ${ }^{19}$.

O fim da eqüidistância e pragmática posição do governo brasileiro encerraram-se, nos últimos meses de 1941, com o completo reequipamento econômico e militar do país. E com o ataque japonês a base americana no Havaí de Pearl Harbor em 7 de dezembro de 1941, mobilizou os governos latino-americanos em solidariedade aos Estados Unidos. E em janeiro de 1942 aconteceu a Reunião de Chanceleres do Rio de Janeiro. Foi aprovada uma moção que recomendava o rompimento das relações com o Eixo, contrariando a posição norte-americana de obter um rompimento unânime com as relações do continente com os países do Eixo, entretanto, a resistência dos argentinos impediu os objetivos americanos (MOURA: 1980, p. 139 e 162).

O ano de 1942 correspondeu também a uma virada do ponto de vista econômico no Brasil. "Acelerou-se o crescimento industrial; pela primeira vez, desde a década de 20, começaram a acumular-se reservas cambiais em função da expansão do programa aliado de aquisição de materiais estratégicos; observa-se a entrada de capitais privados norte-americanos após longo período de desinteresse" (Abreu: 1990, p. 95).

Em 1942, foi criada a Companhia Vale do Rio Doce, para a exploração das jazidas de ferro de Minas Gerais. Em 1943, foi à vez da Companhia Nacional de

$19 \square$ Informações subtraídas do http://www.cpdoc.fgv.br/dhbb/verbetes_htm/5458_24.asp, Acessado em $10 / 04$. 
Artigo original

Hegemonia - Revista Eletrônica de Relações Internacionais do Centro Universitário Unieuro

ISSN: 1809-1261

UNIEURO, Brasília, número 5, 2010

Álcalis, para a produção de soda e barrilha, e da Fábrica Nacional de Motores e em novembro de 1943, o Plano Sousa Costa, aprovado pelo governo norte-americano, iria reduzir consideravelmente o volume da dívida e o pagamento de juros pelo Brasil. Por fim, em 1945, foi constituída a Companhia Hidrelétrica do São Francisco ${ }^{20}$.

Com a não-observação da neutralidade brasileira, houve represália por parte de Hitler. A partir de fevereiro os navios mercantes brasileiros foram alvo de ataque dos submarinos do Eixo (alemães e italianos) na costa do país, com a finalidade de interromper o transporte marítimo entre o Brasil e países do Atlântico Norte, causando centenas de perdas humanas ${ }^{20}$. No mesmo mês Getúlio permite o envio por parte dos norte-americanos de pessoal técnico às bases aéreas de Belém, Natal e Recife; e os americanos solicitaram autorização para ampliar a pista do aeroporto de Fernando de Noronha (FAUSTO: 2006).

Em junho de 1942, com base na orientação nacionalista então manifestada pelo governo brasileiro, cria-se, a Companhia Vale do Rio Doce com a colaboração dos Estados Unidos e da Inglaterra, para impulsionar a exploração das riquezas minerais do subsolo brasileiro, principalmente o ferro ${ }^{21}$.

"As dos submarinos alemães se encarregaram de definir de uma vez por todas a política externa em face da guerra. O torpedeamento de navios brasileiros transportando passageiros, em agosto de 1942, com a morte de 610 pessoas em apenas três dias, provocou indignação geral" (FAUSTO: 2006, p.104). No dia 21 do mesmo mês, Vargas enviou nota comunicando à Alemanha e à Itália que os atos tinham criado

20 Informações subtraídas do site: http://www.cpdoc.fgv.br/nav historia/htm/anos3745/ev_estecon001.htm, Acessado em 10/11. 21 Informações subtraídas do site: http://www.cpdoc.fgv.br/nav_historia/htm/anos3745/ev_estecon001.htm, Acessado em 10/11. 
Artigo original

Hegemonia - Revista Eletrônica de Relações Internacionais do Centro Universitário Unieuro

ISSN: 1809-1261

UNIEURO, Brasília, número 5, 2010

um estado de beligerância e no dia 31 do mesmo mês o governo decreta estado de guerra em todo território nacional ${ }^{22}$.

De acordo com Cervo (1992), os Estados Unidos e a Inglaterra eram contrários a participação do Brasil diretamente no conflito. Todavia, para o projeto político de Vargas era importante que o Brasil participasse do conflito: fortalecer as Forças Armadas Brasileiras internamente a aos olhos dos vizinhos, principalmente a Argentina; garantir a continuidade do apoio militar; e assegurar uma posição significativa no concerto internacional do pós-guerra. O Brasil foi o único entre os países da América Latina a enviar tropas ao conflito. Porém, as vitórias no norte da África pelos aliados diminuíram a importância do Nordeste brasileiro.

Entretanto, em uma visita do presidente americano Franklin Rovosevelt a Natal, Vargas insistiu no interesse do Brasil em participar ativamente do combate e no fornecimento do material bélico prometido, e com aval de Washington às forças brasileiras iriam participar ativamente dos combates da Segunda Guerra Mundial (CERVO: 1992).

O emblema das forças expedicionárias brasileiras era uma cobra fumando, uma alusão as pessoas que considerava que era mais fácil ver uma cobra fumar do que às tropas do Brasil participar da guerra. O comando das tropas foi entregue ao generalde-divisão João Batista Mascarenhas de Morais. Diversos oficiais fora treinar nos Estados Unidos para familiarizar com os métodos americanos ${ }^{23}$.

As forças terrestres incorporaram ao comando norte-americano, que forneceram: armamentos, suprimentos, garantia das linhas de comunicações e material 22 Informações subtraídas do http://www.cpdoc.fgv.br/nav_historia/htm/anos3745/ev_brnaguerra001.htm, Acessado em 10/11. 23 Informações subtraídas do http://www.cpdoc.fgv.br/nav_historia/htm/anos3745/ev_brnaguerra_feb.htm, Acessado em 10/11. 
Artigo original

Hegemonia - Revista Eletrônica de Relações Internacionais do Centro Universitário Unieuro

ISSN: 1809-1261

UNIEURO, Brasília, número 5, 2010

para treinamento. Já a nossa Marinha de Guerra estava em uma situação crítica, mal equipada. Ao ponto que à Quarta Esquadra norte-americana, forneceu instruções técnicas e unidades navais. Coube a Marinha brasileira a tarefa de dar proteção aos navios mercantes nacionais. A Força Aérea Brasileira (FAB), também recebeu treinamentos norte-americanos, que forneceram bolsas de estudos aos brasileiros. E ao entrar no conflito os Estados Unidos forneceram aviões de instruções, e encontra partida o Brasil concedeu permissão para a utilização das bases do nordeste (CERVO: 1992).

Ao final de 1943, decidiram que a FAB participaria diretamente do conflito, através de um grupo de caças ("Senta a Pau" e a "Olho Nele"), participando de operações no Mediterrâneo. O primeiro Escalão era composto por cinco mil homens, chefiado pelo general Zenóbio da Costa, o segundo Escalão pelos generais Osvaldo Cordeiro de Farias e o terceiro por Olímpio Falconière da Cunha. Ao todo, o Brasil enviou a Itália 25 mil homens ${ }^{24}$.

As forças brasileiras integraram-se ao $\mathrm{V}$ Exército norte-americano, comandado pelo general Mark Clark, que por sua vez fazia parte do X Grupo de Exércitos Aliados. As primeiras vitórias da FAB aconteceram em setembro de 1944 com a ocupação Massarosa, Camaiore e Monte Prano. E com a participação da conquista de Monte Castelo, Castelnuovo e Montese. Em 8 de maio a guerra acabou na Europa, o Brasil deixa sepultado na Itália 454 mortos. E em 1945 termina a guerra com as Bombas atômicas jogadas em Hiroshima e Nagasaki pelos Estados Unidos ${ }^{25}$.

\section{Considerações Finais}

$24 \quad$ Informações subtraídas do http://www.cpdoc.fgv.br/nav_historia/htm/anos3745/ev_estecon001.htm

$25 \quad \square$ Informações subtraídas do http://www.cpdoc.fgv.br/nav_historia/htm/anos3745/ev_brnaguerra_feb.htm. 
Artigo original

Hegemonia - Revista Eletrônica de Relações Internacionais do Centro Universitário Unieuro

ISSN: 1809-1261

UNIEURO, Brasília, número 5, 2010

Buscamos mostrar ao longo do texto os caminhos percorridos pela política externa do Estado Novo, entre ás véspera da Segunda Guerra Mundial até 1945. Período de relativa articulação do governo brasileiro que abriu novas possibilidades de desenvolvimento para o Brasil. Focamos atenção no projeto de desenvolvimento calcado na industrialização do país e na utilização da política externa como instrumento de desenvolvimento.

À época, parecia factível ao projeto de desenvolvimento, pois nem os Estados Unidos e nem Alemanha se interessaram pelo projeto brasileiro, entretanto, com o advento da Segunda Guerra Mundial e do acirramento das disputas internacionais e do avanço das ideologias nacionalistas, propícia uma via para o projeto de Vargas.

Segundo Maquiavel (2001), a virtú é a capacidade de adaptação do indivíduo político aos acontecimentos que levaria á permanência no poder. A fortuna representa às circunstâncias, as coisas inevitáveis que acontecem aos seres humanos, é a sorte da pessoa. Vargas sem dúvida foi um virtuoso, desde 1930 até 1945 se manteve no poder. E teve fortuna, principalmente, na evolução do cenário internacional, com a eclosão da Segunda Guerra Mundial, e que Getúlio com maestria soube tirar vantagem para o desenvolvimento do Brasil e ficou ao lado dos Estados Unidos.

Vargas mostrou-se um avio articulador, demonstrado no discurso de 11 de junho de 1941, um algoz negociador baseando-se em princípios maiores do que sua admiração pelos regimes totalitários, permitindo-lhe ser imparcial, e ao mesmo tempo pragmático e ambíguo em sua posição entre os regimes democráticos (Aliados) e os regimes autoritários (Eixo). Conseguindo alcançar seus objetivos para o desenvolvimento do Brasil. 
Artigo original

Hegemonia - Revista Eletrônica de Relações Internacionais do Centro Universitário Unieuro

ISSN: 1809-1261

UNIEURO, Brasília, número 5, 2010

\section{BIBLIOGRAFIA:}

ABREU, M. de P. A Ordem do Progresso - Cem anos de Política Econômica Republicana 1889-1989. 14º ed. Rio de Janeiro. Editora, Campus, 1990.

CERVO, Amado, BUENO, Clodoaldo - História da Política Externa do Brasil. Editora Ática, 1992.

FAUSTO, Boris - História do Brasil. São Paulo: Edusp, 1995.

Letras, 2006.

Perfis brasileiros Getúlio Vargas por Boris Fausto. Editora Companhia das

MAQUIAVEL, Nicolau - O Príncipe de Maquiavel. Tradutor: GOLDWASSER, Maria Julia. $6^{\circ}$ ed. São Paulo. Editora, Martins Fontes, 2001.

MOTA, Myriam Becho e BRAICK, Patrícia Ramos - História das Cavernas ao Terceiro Milênio. $1^{\circ}$ ed. São Paulo. Editora, Moderna, 1998.

MOURA, Gerson - Autonomia na Dependência - A Política Externa Brasileira de 1935 a 1942. Rio de Janeiro. Editora, Nova Fronteira, 1980.

Sucessos e Ilusões - Relações Internacionais do Brasil durante e após a Segunda Guerra Mundial. Rio de Janeiro. Editora, Fundação Getúlio Vargas, 1991.

NOGUEIRA, J. P., MESSARI, Nizar - Teoria das Relações Internacionais - Correntes e Debates. Rio de Janeiro. Editora, Elsevier, 2005.

SARFATI, Gilberto - Teoria de Relações Internacionais. São Paulo. Editora Saraiva, 2005.

Dicionário:

BOBBIO, Norberto- Dicionário de Política - CD-ROM. Brasília.Editora UNB,2003. MOISES, Massaud - Dicionário de Termos Literários - (em Português). Editora cultrix , 1978.

Sites de Pesquisa:

MARCONDES, Danilo. Desfazendo Mitos sobre a Pragmática. Em:

http://publique.rdc.puc-rio.br/revistaalceu/media/alceu_n1_Danilo.pdf Acessado:

23/11/2008.

SIMÕES, Magro, Breno-. Política Pendular em Relações Internacionais na Era Vargas de 1930 a 1945 - O Comércio Exterior á Luz da Teoria Política de Ator Racional. Em:

$<$ http://bdtd.bce.unb.br/tedesimplificado/tde_busca/arquivo.php?codArquivo=1868> , Acessado em: 02/04/2009.

Fundação Getúlio Vargas - CPDOC. Radicalização Política. Em:

<http://www.cpdoc.fgv.br/nav_historia/htm/anos30-37/ev_radpol_aib.htm >. Acessado em 10/11/2008.

Fundação Getúlio Vargas - CPDOC. Golpe de Estado. Em:

$<$ http://www.cpdoc.fgv.br/nav_historia/htm/anos30-37/ev_golpe_estado.htm>.

Acessado em 9/11/2008.

Fundação Getúlio Vargas - CPDOC. Estado de Sítio. Em:

<http://www.cpdoc.fgv.br/nav_historia/htm/glossario/ev_gl_estadositio.htm>. Acessado em 10/04/2009. 
Artigo original

Hegemonia - Revista Eletrônica de Relações Internacionais do Centro Universitário Unieuro

ISSN: 1809-1261

UNIEURO, Brasília, número 5, 2010

Fundação Getúlio Vargas - CPDOC. Estado de Guerra. Em:

<http://www.cpdoc.fgv.br/nav_historia/htm/glossario/ev_gl_estadoguerra.htm> , Acessado em 10/04/2009.

Fundação Getúlio Vargas - CPDOC. Missão Aranha. Em:

<http://www.cpdoc.fgv.br/nav_historia/htm/anos37-45/ev_estecon_aranha.htm> ,

Acessado em 10/04/2009.

Fundação Getúlio Vargas - CPDOC. O DIP e a construção do Estado Nacional.

Em:<http://www.cpdoc.fgv.br/nav_historia/htm/glossario/ev_gl_estadositio.htm>. Acessado em 10/04/2009.

Fundação Getúlio Vargas - CPDOC._Força Expedicionária Brasileira (FEB). Em: < http://www.cpdoc.fgv.br/nav_historia/htm/anos37-45/ev_brnaguerra_feb.htm>.

Acessado em 10/11/2008.

Ordem dos Advogados do Brasil - A Lei de Segurança Nacional. Em:

$<$ http://www.oab.org.br/hist_oab/primeiros_anos.htm,> Acessado 10/03/2009.

Instituto Legislativo Brasileiro - Senado Federal. Era Vargas reduz papel do Senado. Em:<http://www.senado.gov.br/comunica/historia/Rep09.htm>, Acessado 11/11/2008.

http://www.marxists.org/portugues/dicionario/verbetes/k/krupp.htm, Acessado: 15/11. http://farolpolitico.blogspot.com/2007/05/ambiguidade.html, Acessado11/11 